\title{
Research on the path of railway infrastructure's impact on technological
}

\section{progress}

\section{_Empirical analysis based on Chinese Provincial Panel Data}

\author{
Xuhang Bao \\ School of Economics and Management, Beijing Jiaotong University, Beijing 100044, China.
}

726895160@qq.com

Keywords: Railway infrastructure, Technical progress, Malmquist.

\begin{abstract}
Based on China's provincial panel data for 2000-2016 years, this paper uses the Malmquist index method to measure China's technology progress index. The direct and indirect effects of railway infrastructure on technological progress are measured by the panel data analysis model with cross terms. The results show that: Although slower technological progress is the main reason to hinder China's TFP growth, this problem is improving significantly in recent years. Obviously, railway infrastructure has a direct effect on technological progress. Technology import is the main way of technological progress in China, and international trade is the main way of technology import. The smaller the density of railway infrastructure is, the more obvious the impact of international trade on technological progress is.
\end{abstract}

\section{Introduction}

The main path of technological progress in a country or region is self-dependent innovation and technology import. Self-dependent innovation is a kind of creative activity relative to technology import and imitation innovation. It emphasizes the core position of self-dependent intellectual property rights. It refers to the process of realizing the improvement of production level and the valueadded of product value through the technological breakthrough with self-dependent intellectual property rights. Technology import refers to the enterprises, research units and institutions in one country or region to obtain advanced and applicable technology from other enterprises, research units and institutions in other countries or regions.

The impact of transportation infrastructure construction on technological progress can be divided into direct and indirect effects. For example, the research and development process that is formed when improving the technology of transportation facilities can be applied to other areas in need of the transportation industry itself, so as to promote technological progress in other industries. The above effects can be attributed to the direct effect of traffic infrastructure on technological progress $[1,2]$. In addition, the construction of traffic infrastructure can improve the diffusion rate of technology by reducing the barriers and promoting the communication between regions, which is the indirect effect of transportation infrastructure on technological progress [3-5].

In recent years, remarkable achievements have been made in railway construction in China. In 2016 alone, a total of $3281 \mathrm{~km}$ of new lines, $3612 \mathrm{~km}$ of double track lines and $5899 \mathrm{~km}$ of electrified railways were put into operation. Whether China's large-scale railway infrastructure construction has a direct effect on regional technological progress? Can it promote technology proliferation by 
promoting international trade and foreign trade cooperation, such as international trade or foreign direct investment? In order to answer these questions, this study will build an empirical analysis of cross panel data model including traffic infrastructure construction and regional economic and trade cooperation indicators.

\section{Measurement of Technological Progress}

Generally, there are three dimensions of total factor productivity. The first one is the technical change (TC) representing the overall displacement of the production frontier. The second dimension is the scale efficiency $(\mathrm{SECH})$ that represents whether it reaches the optimal production scale. The third dimension is whether the purely technical efficiency (PECH) achieves the maximum input-output ratio under variable-scale compensation conditions. This paper selects the technology change in TFP theory as a specific index to measure the level of technological progress.

Calculation Method. Currently, the DEA method is the most basic analysis method in efficiency measurement. However, since the DEA method can only calculate the efficiency of time series and cross section data, it has not been applied to the research of efficiency measurement based on panel data. In 1994, Fare, Crosskopf et al. combined the data envelopment analysis (DEA) theory with the nonparametric linear programming method in this theory to establish the Malmquist index for observing total factor productivity growth (total factor productivity change, TFPch) at two different periods. It makes up for the insufficiency of the static DEA model which can't analyze the panel data, making the Malmquist index widely used [6]. Its calculation formula is as follows:

$$
M_{i, t+1}\left(X_{i}^{t+1}, Y_{i}^{t+1}, X_{i}^{t}, Y_{i}^{t}\right)=\left[\frac{D_{i}^{t+1}\left(X_{i}^{t+1}, Y_{i}^{t+1}\right)}{D_{i}^{t+1}\left(X_{i}^{t}, Y_{i}^{t}\right)} * \frac{D_{i}^{t}\left(X_{i}^{t+1}, Y_{i}^{t+1}\right)}{D_{i}^{t}\left(X_{i}^{t}, Y_{i}^{t}\right)}\right]^{\frac{1}{2}}
$$

In the formula, i represents the location, t means time, $D_{i}^{t+1}\left(X_{i}^{t}, Y_{i}^{t}\right)$ and $D_{i}^{t}\left(X_{i}^{t}, Y_{i}^{t}\right)$ are the distance functions of two periods, $D_{i}^{t+1}\left(X_{i}^{t+1}, Y_{i}^{t+1}\right)$ and $D_{i}^{t}\left(X_{i}^{t+1}, Y_{i}^{t+1}\right)$ are two intertemporal distance functions.

The type 1 can be further decomposed:

$$
M_{v, c}^{t, t+1}=\left[\frac{D_{v}^{t+1}\left(X_{i}^{t+1}, Y_{i}^{t+1}\right)}{D_{v}^{t}\left(X_{i}^{t}, Y_{i}^{t}\right)}\right] *\left[\frac{D_{v}^{t}\left(X_{i}^{t}, Y_{i}^{t}\right)}{D_{c}^{t}\left(X_{i}^{t}, Y_{i}^{t}\right)} / \frac{D_{v}^{t+1}\left(X_{i}^{t+1}, Y_{i}^{t+1}\right)}{D_{c}^{t+1}\left(X_{i}^{t+1}, Y_{i}^{t+1}\right)}\right] *\left[\frac{D_{c}^{t}\left(X_{i}^{t+1}, Y_{i}^{t+1}\right)}{D_{c}^{t+1}\left(X_{i}^{t+1}, Y_{i}^{t+1}\right)} * \frac{D_{c}^{t}\left(X_{i}^{t}, Y_{i}^{t}\right)}{D_{c}^{t+1}\left(X_{i}^{t}, Y_{i}^{t}\right)}\right]^{\frac{1}{2}}
$$

In the upper form, the first component $\left[\frac{D_{v}^{t+1}\left(X_{i}^{t+1}, Y_{i}^{t+1}\right)}{D_{v}^{t}\left(X_{i}^{t}, Y_{i}^{t}\right)}\right]$ refers to the pure technical efficiency change index, referred to as PECH, and the second component $\left[\frac{D_{v}^{t}\left(X_{i}^{t}, Y_{i}^{t}\right)}{D_{c}^{t}\left(X_{i}^{t}, Y_{i}^{t}\right)} / \frac{D_{v}^{t+1}\left(X_{i}^{t+1}, Y_{i}^{t+1}\right)}{D_{c}^{t+1}\left(X_{i}^{t+1}, Y_{i}^{t+1}\right)}\right]$ refers to the scale efficiency change index, referred to as $\mathrm{SECH}$, and the third component $\left[\frac{D_{c}^{t}\left(X_{i}^{t+1}, Y_{i}^{t+1}\right)}{D_{c}^{t+1}\left(X_{i}^{t+1}, Y_{i}^{t+1}\right)} * \frac{D_{c}^{t}\left(X_{i}^{t}, Y_{i}^{t}\right)}{D_{c}^{t+1}\left(X_{i}^{t}, Y_{i}^{t}\right)}\right]^{\frac{1}{2}} \quad$ refers to the technical change index, referred to as TC.

$\mathrm{PECH}$ expresses the pure technological change rate under variable scale income, reflects the change of enterprise management level and system level. When $\mathrm{PECH}>1$, it indicates that the management level and system level have been improved, and it plays a promoting role in improving the production efficiency of the enterprise. SECH represents a change in scale efficiency. When $\mathrm{SECH}>1$ (equal to or less than 1), it indicates that the decision-making unit shows a scale of 
economies of scale (or the scale is uneconomical). TC indicates the change of technology. When $\mathrm{TC}>1$, it shows that the front surface of production has moved upward, that is, technological progress has been made.

Variable and Data Description. This study mainly measures the total factor productivity in the mainland of China. Due to the serious lack of relevant data in Tibet, Hong Kong, Macao and Taiwan, and the city of Chongqing was listed as a municipality directly under the central government in 1997, it is not suitable for separate analysis of the stock of material capital. Therefore, in order to keep the consistency and integrity of the statistical caliber, the above areas are not included in the analysis framework. To sum up, the main research object of this study is the sample of 29 regions in the mainland of China for 2000-2016 years. Except in particular, all the original data are from the China Statistical Yearbook, the China Compendium of Statistics 1949-2008, the China Population \& Employment Statistics Yearbook and the local statistical yearbook in the corresponding years.

Output variable: The logarithmic form of the output variable in the DEA model in this paper is expressed as the actual gross national product of China's provinces from 2000 to 2016 calculated in 2000 as the base period.

Input variable: (1) Capital investment: This paper selects fixed assets investment as a measure of capital stock, and also eliminates the price factor using the 2000 data as the base period. (2) Labor input: In this paper, the total number of people employed in the whole province at the end of each year is the index of labor input.

Calculation Results and Analysis. The results of China's total factor productivity change over the years are shown in table 3-2. In the past 2000-2016 years, China's total factor productivity has shown a downward trend as a whole, and the TFP index has decreased by 1.4 percentage points. The main factor that hinders the increase of total factor productivity is the rate of technological progress. During the study period, the technical progress value (TC) was only 0.991 , and the pure technical efficiency value $(\mathrm{PECH})$ and the scale efficiency value $(\mathrm{SECH})$ decreased less, by $0.3 \%$ and $0.2 \%$ respectively. From the specific changes in each year, the TFP change rate shows a trend of "U" shape change as a whole. Affected by the international financial crisis, 2009 was the largest drop in total factor productivity in China during the study period. The TFP index was only 0.965 . After that, it has increased year by year. And the number of TFP refers to more than 0.990 after 2014. There is no obvious change trend in $\mathrm{PECH}$, but the variation trend of SECH and TC is obvious. TC overall shows an upward trend in the study period. In the seven year of 2010-2016, the TC index has a value greater than 1 in four years and the other three years are above 0.990. In contrast to TC, SECH shows a trend of overall decline. In the eight years of 2000-2007 Years, the scale efficiency index was greater than 1 in seven years. But after the outbreak of the financial crisis in 2008, the SECH value was less than 1 . 


\begin{tabular}{cccccc}
\hline Year & TC & PECH & SECH & TFP & Year \\
\hline 2000 & 0.983 & 1.002 & 1.004 & 0.989 & 2000 \\
2001 & 0.977 & 1.001 & 1.007 & 0.984 & 2001 \\
2002 & 0.985 & 0.995 & 1.000 & 0.981 & 2002 \\
2003 & 0.989 & 0.992 & 0.994 & 0.976 & 2003 \\
2004 & 0.986 & 0.998 & 1.001 & 0.985 & 2004 \\
2005 & 0.983 & 0.996 & 1.001 & 0.980 & 2005 \\
2006 & 0.974 & 1.000 & 1.006 & 0.980 & 2006 \\
2007 & 0.984 & 0.997 & 1.003 & 0.984 & 2007 \\
2008 & 0.999 & 0.996 & 0.997 & 0.992 & 2008 \\
2009 & 0.989 & 0.988 & 0.988 & 0.965 & 2009 \\
2010 & 1.004 & 0.996 & 0.990 & 0.989 & 2010 \\
2011 & 1.009 & 0.999 & 0.993 & 1.001 & 2011 \\
2012 & 0.993 & 0.998 & 0.995 & 0.987 & 2012 \\
2013 & 0.993 & 0.998 & 0.996 & 0.988 & 2013 \\
2014 & 0.990 & 1.002 & 0.999 & 0.991 & 2014 \\
2015 & 1.000 & 0.996 & 0.995 & 0.992 & 2015 \\
2016 & 1.004 & 0.997 & 0.997 & 0.998 & 2016 \\
$2000-2016$ & 0.991 & 0.997 & 0.998 & 0.986 & 2016 \\
\hline
\end{tabular}

\section{An Empirical Analysis of the Impact of Railway Infrastructure on Technological Progress}

Model Setting and Variable Description. Railway infrastructure variables: This paper uses the physical representation of railway infrastructure construction stock for empirical analysis. The specific index is the railway density (Railway): mileage of railway operation per 10000 people.

Dependent variable: We use the TC index of China's provinces during the study period in the last section of this article.

Core explanatory variables: Trade, investment and other economic activities are the main way of technology spillover effect, and also the main way of technological progress in developing countries. This chapter uses the two variables of trade dependence degree (Trade) and foreign direct investment degree (FDI) to represent the openness of the commodity market and the capital market. The trade dependence degree is equal to each region's total imports and exports divided by the current period of the region. The variable of foreign dependence degree is equivalent to the FDI in each region divided by the gross output of the region in the current period.

Control variables: Based on existing literature research, the control variables selected in this chapter include scientific research input, education level, industrial structure, financial development level, government expenditure level, marketization degree, opening level and urbanization level, etc.

Research input variables: The improvement of technical level is inseparable from the investment of scientific and technological research and development. In addition to the technological diffusion of the central countries or regions, regional scientific and technological innovation is also an important way for its own research and development. In this study, R\&D funds (RK) and full-time personnel converted from the persons engaged in R\&D (RER) of industrial enterprises above designated size were selected as research input variables.

The level of Education (Edu): The level of education is an important factor affecting the technological progress of a region. This study selects the average number of years of education as a variable of human capital. The specific calculation method is to first calculate the proportion of the 
population of primary school degree, junior high school degree, high school degree, college degree or above in the population aged 6 and over in the statistical yearbook. Then these weights are multiplied by $6,9,12$, and 16 , respectively, and finally summed.

Industrial structure variable (Industry): Industry is the carrier and platform of technological innovation, and the real economy, especially the manufacturing industry, has produced the demand pull effect for technological innovation, and also provides the accumulation of technological innovation. This research chooses the proportion of the second industry output value to GDP as the industrial structure variable.

Development variable of the financial industry (Fin): The developed financial industry can provide the necessary financial support for technological innovation. This study uses the balance of the yearend deposit and loans of regional financial institutions to account for the proportion of the region's GDP as the proxy variable of the level of financial development.

Urbanization level (Urban): The Chinese economy has always had significant dual economic characteristics. The difference between urban economy and rural economy is huge. The impact of urban economy on technological innovation is obviously more significant. In this study, the proportion of non-agricultural population in the whole population is used as the proxy variable of the index.

In order to investigate the impact of different transportation infrastructure construction and international economic cooperation on regional technological progress, the following econometric models were constructed.

$$
y_{i t}=\beta_{0}+\beta_{1} \text { commerce }_{i, j}+\beta_{2} \text { railway }_{i, j}+\beta_{3} \text { commerce }_{i, j} * \text { railway }_{i, j}+\beta_{4} x_{i, j}+\mu_{i}
$$

Commerce expressed two economic cooperation core variables of Trade and FDI. Railway is the stock index of railway infrastructure. Commerce*Railway is the cross item between the core variables of economic cooperation and the stock of transport infrastructure construction. $\mathrm{X}$ was the control variables, including RK, RER, Edu, Industry, Fin and Urban.

Empirical Test and Result Analysis. Trade and FDI were used as core variables for panel regression respectively. The empirical results are shown in Table 2. The results of Hausman test in the table showed strong rejection of the original hypothesis in all equations, indicating that the fixed effect analysis of the model was more appropriate.

First of all, the direct effect of railway transport infrastructure on technological progress is analyzed. Observing the regression coefficient of railway infrastructure in each equation, we can see that the impact of Railway on technological progress is significantly positive, with a coefficient of 0.035. In recent years, with the constant innovation of China's standard EMU and the continuous improvement of high-speed railway network construction, the railway transportation industry has been making great progress in technology. With the diffusion of technology among industries, the role of Railways in promoting China's technological progress is expected.

Secondly, it analyzes the direct impact of regional economic and trade cooperation on technological progress. As mentioned above, scholars generally believe that international trade and interregional construction activities are important ways to technology diffusion. The regression coefficient of trade and FDI in each equation shows that international trade has played a driving role in regional technological progress, and all of them have passed the significant test on the $1 \%$ level. The influence of FDI on regional technological progress is not significant, and the only regression coefficient through the significance test is -0.011 . There are three reasons for the different effects of international trade and foreign direct investment on technological progress. On one side, as proposed by Yi Gang and Fang Gang (2003), the introduction of technology and the purchase of equipment 
from developed countries are the main ways of China's technological progress in emerging economies [7]. On the other side, the international market competition for products exporting enterprises is more intense. Foreign markets, especially developed countries, have higher demand levels and higher requirements for products. All these will stimulate the production enterprises to carry out technological innovation and product upgrading. Thirdly, according to the theory of comparative advantage, capital outflow is due to the comparative advantage of capital in the country. Therefore, it is necessary to cooperate with countries with comparative advantages in terms of labor factors and technological elements to earn more profits. The factor of labor force is one of the most significant comparative advantages of China's industrial development for a long time, so the foreign direct investment will naturally focus on the labor intensive industries in China. In 2005, 11 of the 17 industrial sectors in which China's foreign-funded enterprises were above the average level were labor intensive industries. Although the level of China's economic development is constantly improving and the process of industrial transformation is accelerating, the comparative advantage of China in the global economy has not changed radically. Foreign direct investment is still dominated by traditional industries, but China's traditional industry technology is relatively mature, so FDI has a limited role in promoting China's technological progress.

Table 2 Empirical Analysis of the Impact of Railway Infrastructure Investment on Technological Innovation

\begin{tabular}{|c|c|c|c|c|}
\hline \multirow{2}{*}{ variable } & \multicolumn{2}{|c|}{ Trade } & \multicolumn{2}{|c|}{ FDI } \\
\hline & fixed effect & random effect & fixed effect & random effect \\
\hline \multirow{2}{*}{$\mathrm{Edu}$} & $0.006^{* * *}$ & 0.005 & $0.009 * * *$ & 0.004 \\
\hline & (2.03) & $(1.62)$ & $(2.89)$ & $(1.38)$ \\
\hline \multirow{2}{*}{ Industry } & $-0.059 * * *$ & $-0.067 * * *$ & $-0.054 * * *$ & $-0.063 * * *$ \\
\hline & $(-16.78)$ & $(-21.70)$ & $(-14.16)$ & $(-19.27)$ \\
\hline \multirow{2}{*}{ Fin } & $-0.006 * *$ & -0.003 & -0.002 & -0.001 \\
\hline & $(-2.24)$ & $(-1.31)$ & $(-0.74)$ & $(-0.52)$ \\
\hline \multirow{2}{*}{ Urban } & -0.011 & $0.155 * * *$ & 0.047 & $0.236 * * *$ \\
\hline & $(-0.25)$ & (4.27) & (1.03) & $(7.42)$ \\
\hline \multirow{2}{*}{ RK } & -0.002 & $-0.003 * *$ & -0.002 & $-0.003 * *$ \\
\hline & $(-1.60)$ & $(-2.17)$ & $(-1.64)$ & $(-2.53)$ \\
\hline \multirow{2}{*}{ Trade } & $0.085 * * *$ & $0.075 * * *$ & & \\
\hline & $(2.84)$ & (2.69) & & \\
\hline \multirow{2}{*}{ FDI } & & & -0.004 & -0.005 \\
\hline & & & $(-0.66)$ & $(-0.65)$ \\
\hline \multirow{2}{*}{ Railway } & $0.035 * * *$ & $0.011 * *$ & $0.035 * * *$ & 0.004 \\
\hline & $(5.50)$ & (2.34) & $(2.92)$ & $(0.19)$ \\
\hline \multirow{2}{*}{ FDI*Railway } & & & $-0.002 *$ & -0.001 \\
\hline & & & $(-1.95)$ & $(-0.51)$ \\
\hline \multirow{2}{*}{ Trade*Railway } & $-0.023 * * *$ & $-0.163 * *$ & & \\
\hline & $(-2.80)$ & $(-2.11)$ & & \\
\hline $\mathrm{R}^{2}$ & 0.1179 & 0.5826 & 0.3421 & 0.6220 \\
\hline chi2 & \multicolumn{2}{|c|}{$51.83 * * *$} & \multicolumn{2}{|c|}{$119.62 * * *$} \\
\hline
\end{tabular}

Note: $* * *$, and $* * *$ denote significance at the $10 \%, 5 \%$ and $1 \%$ levels, respectively.

Thirdly, through the observation of the cross terms of the railway infrastructure construction variables and regional economic and trade cooperation variables, it is known that whether it is international trade or foreign direct investment, the greater the density of the railway infrastructure, 
the smaller the impact of international economic and trade cooperation on technological progress. This may be due to the relatively large reserves of transportation infrastructure in China, which are relatively developed areas. The marginal effect of railway infrastructure construction on promoting international trade is significantly weaker than that of less developed areas. Therefore, the coefficient of the cross term is significantly negative.

In other control variables, the industrial structure variable (Industry) is one of the few variables among all the control variables that are passed through the significance test at the $1 \%$ level in each equation. The absolute values of the regression coefficients of Industry are larger than those of other variables. This may be due to the large proportion of traditional industries in China's second industry. According to the data of the China National Bureau of Statistics, the main business income of the industrial enterprises above the scale of the traditional Chinese industry in 2016 is 100520.2 billion yuan, accounting for $86.73 \%$ of the national proportion, and the total profit of the industrial enterprises above the scale is 6162 billion yuan, accounting for $85.68 \%$ of the national proportion. The huge proportion of traditional industries is one of the important factors hindering technological progress. In anticipation, the level of education (Edu) has a significant role in promoting regional technological progress. The impact of RK on technological progress is not significant. This also verifies the view that China's technological progress relies mainly on technology import. Other control variables have no obvious effect on technological progress.

\section{Conclusions}

This paper takes the panel data of 29 regions in China from 2000 to 2016 as the research object, and uses the railway density as the variable to measure the railway infrastructure construction. Based on the foreign direct investment (FDI) and foreign trade dependence (Trade) as the regional economic cooperation variables, this paper constructs a panel regression model and analyzes it. This paper analyzes the direct and indirect effects of transportation infrastructure construction on technological progress. The empirical results show that: (1) During the study period, Chinese total factor productivity (TFP) declined by $1.4 \%$, and the low level of technological progress is the main reason hindering the improvement of total factor productivity (TFP). However, in recent years, the speed of technological progress in China has accelerated significantly in recent years. (2) Technology introduction is the main way for Chinese technological progress, and international trade is the main way of technology introduction. The effect of foreign direct investment on technology introduction is not obvious. (3) Because the rail transit equipment manufacturing industry belongs to the high-end equipment manufacturing industry and it has a strong technology diffusion effect, the railway infrastructure construction has a significant direct prompting effect on technological progress. (4) The area where the density of transportation infrastructure is smaller, the more obvious the promotion of international trade to technological progress. Because such areas are usually relatively backward inland areas, the marginal effects of international trade are greater than in developed areas. (5) The regression coefficient of the secondary industry's proportion to technological progress is negative and significant. This shows that the mature technology level of traditional industries and the development inertia brought by the huge scale are one of the important factors hindering regional technological progress.

\section{References}

[1] Hu Angang, Liu Shenglong. Transportation, Economic Growth and Spillover: Conclusion Based on Spatial Econometrics[J]. China Industrial Economics, 2009, (05):5-14. 
[2] Liu Binglian, Wu Peng, Liu Yuhai. Transportation Infrastructure and the Increase in TFP in China-Spatial Econometric Analysis on Provincial Panel Data [J]. hina Industrial Economics, 2010, (03):54-64.

[3] Pradhan R P, Bagchi T P. Effect of transportation infrastructure on economic growth in India: the VECM approach [J]. Research in Transportation Economics, 2013, 38(1): 139-148.

[4] Behrens K. International integration and regional inequalities: how important is national infrastructure? [J]. The Manchester School, 2011, 79(5): 952-971.

[5] Fujita M, Krugman P R, Venables A J. The spatial economy: Cities, regions, and international trade[M]. MIT press, 2001.

[6] Fare R, Rolf F, Grosskopf S, et al. Production frontiers [M]. Cambridge University Press, 1994.

[7] Yi Gang, Fan Gang, Li Yan. A Theoretical Analysis on Economic Growth in China and Total Factor Productivitu [J]. Economic Research Journal, 2003, (08):13-20+90. 